\title{
Cascading Events, Technology and the Floods Directive: future challenges
}

\author{
Gianluca Pescaroli ${ }^{1}$, Michael Nones ${ }^{2, a}$ \\ ${ }^{1}$ Institute for Risk and Disaster Prevention, University College London, Gower Street, WC1E 6BT, London, United Kingdom \\ ${ }^{2}$ gerstgraser - Ingenieurbüro für Renaturierung, An der Pastoa 13, 03042, Cottbus, Germany
}

\begin{abstract}
Cascading events can be referred to multidimensional disasters, where a primary trigger generates a nonlinear series of secondary emergencies that escalate in time, becoming eventually the priority to tackle. In this process, critical infrastructure can be handled as roots of vulnerabilities, because they accumulate both physical attributes and functional nodes. When compromised, they produce widespread breakdowns of society, but also orient emergency responses and long-term recovery. Although floods have been widely associated to the failure of vulnerable equipments or to the disruption of strategic sectors such as energy, communication and transportation, their integration with the emerging concept of cascading has been limited. This open topic presents many challenges for scholars, researchers and practitioners, in particular when the implementation of the EU Floods Directive is considered. The paper presents an overview of the Floods Directive and its relation with the cascading events, using case studies and examples from the existing literature to point out missing links and gaps in the legislation. Conclusions argue that the Directive considers only local geographical scales and limited temporal horizons, which can be result inadequate to limit the escalation of events.
\end{abstract}

\section{Introduction}

Floods are considered one of the most critical categories of disaster in Europe for their wide and strong recurrence. Over the period 1986-2006, it has caused estimated damages for over 100 billion euro [1, 2]. The potential impact of the phenomena is not only related to environmental (natural) causes, but has also consistent anthropic roots. In the recent decades, economic and insured losses associated with flooding events have drastically increased for their correlation to socioeconomic drivers and political decisions, such as strategies of spatial planning or land use management [3, 4]. Despite the adoption of new mitigation measures, it is probable that the trend will continue for the future. Indeed, on the one hand flood-prone areas remain attractive for human activities and the higher consume of land is likely to increase the damage potential in the near future [1]. On the other hand, it is known that the frequency and magnitude of flooding events may increase because of climate change patterns exacerbated by industrial process and urban pollution [5, 6, 7].

Even though the areas at risk of floods are often wellknown, preparedness levels can be still scarce because of a hierarchical and sectorial planning mentality prevailed for a long time. Flood defense policies had different phases since the Second World War, but the emphasis on non-structural measures becomes prominent only starting from the early nineties [8]. Nowadays, it is unequivocal that the positive impact of technological advances depends also by forms of inclusive governance that could

\footnotetext{
a Corresponding author: nones@gerstgraser.de
}

overcome risk denial, increase the trust in public agencies and improve communications [9]. This process is far from being linear and different authors explained that, even if warning strategies improved since the early 2000s, in some cases they may be still missing the right approach to inform, train and involve water managers and citizens [10]. A recurrent limitation is represented by the integration of top-down and bottom-up approaches, which are often considered only after major disasters, when preparedness measures become a shared priority among all the stakeholders [11]. Similarly, it is known that robustness and flexibility criteria have been not implemented in governance, but are necessary for adapting to long-term environmental changes [12]. As uncertainty dominates future scenarios, decision makers are required to maximize performances by considering the local sensibility to multiple technological and environmental hazards. However, despite many improvements, there are still gaps in the legislation that should support a comprehensive management of risks $[13,14,15]$. For example, the evolution of tools and the choice of political portfolio have been oriented by longterm social backgrounds that are different among countries [16].

In the European Union, some recurrent failures have been found in addressing cross-scale vulnerabilities, such as in the case of communication and cooperation across administrative borders that may result in conflicts between upstream and downstream communities [11]. The implementation of the European Directive on the Assessment and Management of Flood Risks [17], 
hereafter called Floods Directive (FD), directly reflects those problems: although the jurisdiction of the Community is filled by a very substantial amount of transboundary water systems, more uniformity in flood risks assessment and mapping is still needed [18]. The application of the emerging concept of cascading events proposed by Pescaroli and Alexander [19] could represent an additional challenge. In fact, the FD seems to be focused on localized impacts, without adequately addressing the coordination challenges that could arise in the case of cross-scale crisis where cascades are diffused [4]. However, many interrogatives remain open, in particular regarding likelihoods and features of worst case scenarios.

The paper aims to test the hypothesis that the Floods Directive is missing to address the potential escalation of events that distinguishes cascading disasters. After an introduction about the legislative background of the Directive, we present a brief description of cascading events and the role of Critical Infrastructures (CI). A collection of case studies, spanning from urban floods to NaTech events, shows the existing gaps within the FD in addressing the cascading effects triggered by flooding events. Questions on these issues and their integration during the future implementation cycles are discussed and presented in the conclusions, as well as the necessity of further research.

\section{Directive on the Assessment and the Management of Flood Risks}

The European Commission issued a communication on flood risk management in 2004, highlighting the need for further legal actions to limit the damages caused by flooding all over Europe and to improve coordination between and within the Member States. A proposal for a new Directive was released in 2006, after an intense consultation process involving Member States, NGOs, scientific community and other stakeholders. Despite that it passed through various European institutions, it was subjected only to minor modifications and, finally, the Directive on the Assessment and Management of Flood Risks become into force only 17 months after the first reading in the Parliament, on 26 November 2007 [17].

The core problems that this Directive has to handle are: i) floods are natural phenomena that cannot be prevented; ii) floods have the potential to cause displacement of people, fatalities, environmental and economic damages; iii) anthropogenic activities and climate change can contribute to increase probabilities and adverse impacts of floods; iv) measures to reduce flood risks within international river basins should be coordinated on a transnational level; v) measures related to water or land use changes should be verified for their impacts on flood risks [20, 21].

However, many challenges are still open. Birkmann et al. [22] suggested that the FD and its implementation strategy missed the integration of a comprehensive approach on vulnerability and proposed the need to apply a new framework on the topic. This could be true even for cascading events where, according to the model developed by Pescaroli and Alexander [23], the Directive could reduce potential losses, acting as a mediator of cross-scale spreading. Firstly, the reception of lessons learned could be jointed with the acknowledgment of new risks into new forms of good governance that may activate positive feedbacks to attenuate vulnerability and environmental losses [24]. Secondly, the acknowledgement of coupled natural and anthropogenic forcings could be applied at reasonable larger temporal and spatial scales to tackle the vulnerability paths existing between primary triggers and secondary crises [4].

\subsection{Legislative background}

The implementation cycle of the FD follows fixed deadlines, characterized by three steps regularly updated every six years (Figure 1). For the first cycle, these steps were: i) preliminary flood risk assessment, completed in 2011; ii) flood hazard maps and flood risk maps for flood-prone zones, produced in 2013; iii) flood risk management plans, recently completed by the end of 2015.

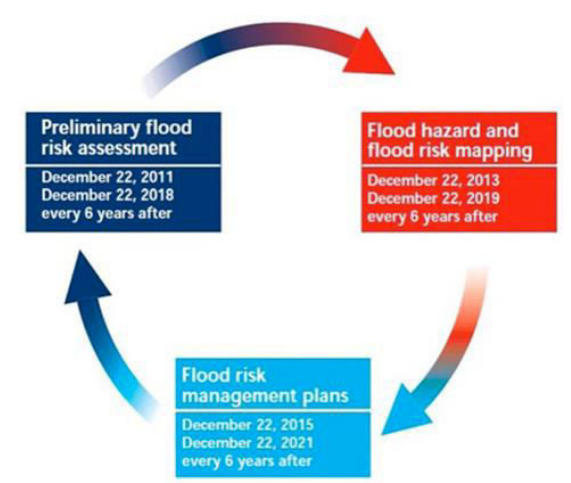

Figure 1. The implementation steps required by the Floods Directive, with relative deadlines.

\subsection{Links with Critical Infrastructure}

Critical Infrastructure (CI) plays a central role in the development of the European well-being [25]. It represents a consistent part of the built environment, and its components can be both concentrated and diffused in space. For example, in the electricity sector generation is assured by localized power plants and the distribution by long range grids. As human settlements are often located in flood-prone areas, CI can be threatened by flooding events, generating consequences that go beyond the flooded regions [26].

Several studies have argued that water management and land use planning are often separate issues for politicians and decision makers [4, 5, 27]. This can involve different management strategies and overlapping of jurisdiction, as well as to inconsistencies in the terminology used [28]. According to Birkmann and Von Teichman [29], when climate change scenarios and extreme events are considered, the norms for adaptation and resilience of $\mathrm{CI}$ should be defined and improved. This includes better information on multi-dimensional vulnerability and capacity mapping that may lead to the creation of dynamic vulnerability assessment processes. 


\section{Cascading events, Critical Infrastructures and multiple stressors}

In this section, we explain the concept of cascading events and derive two vulnerability drivers that could be used to test the European Floods Directive: Critical Infrastructure and multiple stressors in river systems.

\subsection{Cascading events}

The relevance of cascading events and interconnected risks has grown sensibly during the last years. The early approach can be referred to the idea that "toppling dominoes" activate a series of causal chain effects [30]. Other authors (see, as example, [31]) suggested the idea that branching tree of emergencies are triggered by a primary threat. As an example, the vulnerability of society to complex crisis has been highlighted by events such as the air transportation shot down triggered by the 2010 eruption of Eyjafjallajökull and the Fukushima meltdown that hit Japan in 2011.

The increased knowledge of globally networked risks and the sensibility of their interdependencies required a shift in the paradigm of knowledge [32]. Therefore, Pescaroli and Alexander [19] proposed a comprehensive approach to cascading events, arguing that they are distinguished by the existence of unforeseen and nonlinear paths of subsidiary events (Figure 2). The crisis escalates as time progresses, instead of being stabilized by the full mobilization of emergency resources, spreading towards the vulnerabilities of society and the disruption of functional nodes such as CI. Although cascading effects are associated with complex chain failures in human subsystems, cascading events or cascading disasters have a higher level of complexity and escalation where the gravity of the secondary crisis tend to distinguish it from the primary trigger [19].

a)

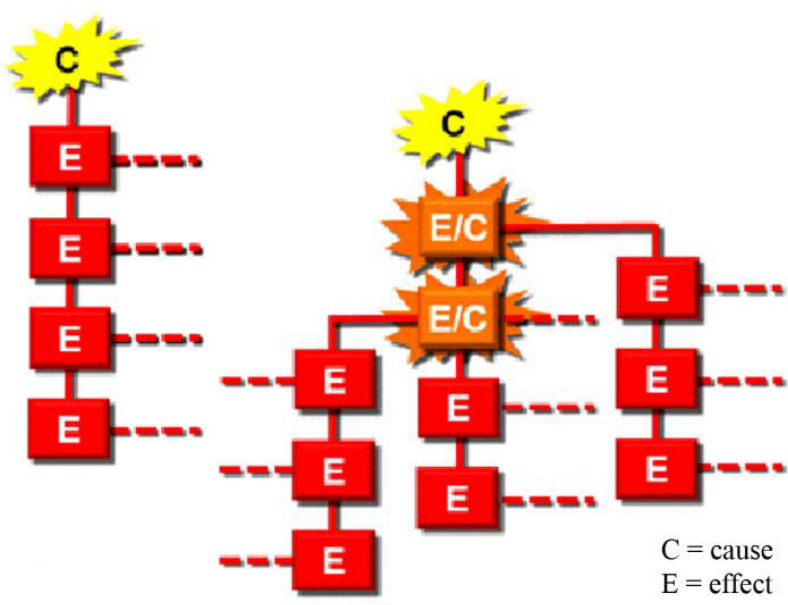

Figure 2. a) Linear path of events in disasters and b) non-linear path of cascading events (adapted from [19]).

Thus, the application of cascading concept to the management of water basins and risk mapping suggested the need to shift from hazards assessment to social vulnerability assessment [4]. This process has different components, and any consideration about multi-hazards interactions in management strategies has to join together environmental and anthropogenic processes [33].

According to Pescaroli and Alexander [23], cascading events are manifested as a consequence of vulnerabilities accumulated in different scales and systemic levels, such as the environment, socio-technological drivers (e.g. globalization or local institutions), or interdependent CI (Figure 3). Consequently, cascades are more dependent by contextual dynamics associated with the pre-existing factors and social feedbacks explained in the model proposed by Alexander [24]. At the micro-scale, they correspond to roots such as corruption, negligence or unsafe conditions of production, which become unsustainable weaknesses of socio-economic models at the macro-scale.

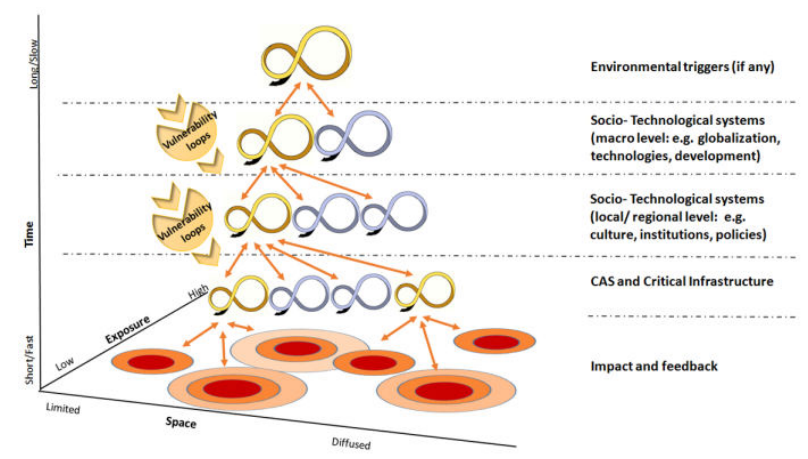

Figure 3. Vulnerability path of cascading disasters and crossscale interactions (adapted from [23]).

\subsection{Critical Infrastructure}

Critical Infrastructure can be seen as the recurrent element where fragilities are accumulated at the microlevel, activating feedbacks to larger scale and acting as systems for their role of functional nodes [23]. Indeed, following the Directive on European Critical Infrastructures (ECIs) released in 2008, these are defined as "an asset [...] which is essential for the maintenance of vital societal functions, health, safety, security, economic or social well-being of people, and the disruption or destruction of which would have a significant impact [...] as a result of the failure to maintain those functions" [25]. According to Hellstrom [34], CI can be seen as technological systems that aggregate functions, but also vulnerabilities and pressures that could be triggered by external hazards. The increase of interconnections among sectors raised the likelihood that localized failures or disruptions could have dramatic impacts at regional or cross-boundary level [35]. Consequently, taken into account the unforeseen nature of crises and the very complex structures of CI networks, mitigation efforts may be inadequate, especially when dealing with the cascading effects of crises [36]. Moreover, the adaptation process of CI to climate change scenario and to extreme events suggest the need of long-term visions that could be integrated in better strategies of planning, preparedness and damages assessment [29]. 


\subsection{Multiple stressors in river systems}

Anthropogenic interventions have contributed to modify several watercourses and floodplains since the beginning of the civilization [37, 38]. In Europe, this process accelerated over the last decades, with heavy consequences for watercourses and their management. Nowadays, it has been recognized that natural and anthropogenic forcings must be considered together, both at the technical and legislative level [4]. This supported the creation of a broad framework of norms covering different needs and vulnerabilities in the territory. At the European level, the first strategy to consider is the Water Framework Directive [39], which includes biological, hydro-morphological and physico-chemical quality elements as a basis to monitor river systems. In addition to this law, the European Commission released the Floods Directive in 2007 [17, 21]. As described above, the main aims of the Directive are the protection and the management of the natural/built environment from flooding events, considering different types of floods, their consequences and the anthropic forcings, as well as the handling of risks associated with flooding events.

\section{Case studies}

The paper analyzes a series of case studies to highlight the importance of applying the Floods Directive at a sufficiently larger scale [4]. The goal is to provide some wider evidences that could support the development of new scenarios, but also improve the existing risk and vulnerability assessment processes. The methodology proposed here is a qualitative comparison of literature, including both academics studies and official documents. This methodology is based on some assumptions:

- the cases can be considered "cascading disasters" according to the definition of Pescaroli and Alexander [19], highlighting disaster paths escalated by CI [23];

- the events describe the different components of flood risk, addressing functional consequences of the escalations and possible impacts of the FD, but also interconnection among hazards and their chemical or biological impact according to current theories $[4,19,23$, 33];

- the time frame is after the introduction of the European Water Framework Directive [39], namely happened in the last 15 years;

- the cases span between European Member States, with the aim to test the general hypotheses with possible local drivers.

The absence of databases on cascading and the emerging literature about this topic have to be considered both as a limitation and a potential for future researchers. On the one hand, our selection was limited by the scarce availability of data, which forced us to considered events and scenarios we were aware of, as already happened in other studies [4]. On the other hand, scholars could take advantages of the status quo and easily improve the state of art using our study as base.

In the next subsections we describe floods in urban areas that can threat industries and economic hubs (Paris case study), while other events can have a delayed impact on different sectors such telecommunications (York case) or drinking water supply (Messina event). We also point out that floods may acts as mechanisms of direct or indirect release of hazardous materials, impacting sensible sites such as chemical power plants (Spolana case) or waste treatment facilities (Gloucestershire case).

\subsection{Cascading in urban areas: Ile-de-France}

Our first case study is focused on the analysis of urban flooding, which is rooted in more than a century of water management policies across Europe.

The Seine River in the Ile-de-France region (France) has been reduced in various stages since 1910 , by means of the implementation of structural measures such as dams, levees and canalization [40]. However, over the last decades, the investments have been very limited, and now the French protection could be considered below the standards of other European countries [40]. The risk exposure and the resulting vulnerability are accentuated by an increased urban density in the economic centre of France, as well as by the development of several activity centres and critical infrastructures along the Seine River [40]. In particular, the Ile-De-France region (Figure 4b) is the second largest economic area in Europe, and represents a logistic hub for the whole France, covering about one third of the economic activities of the entire country.

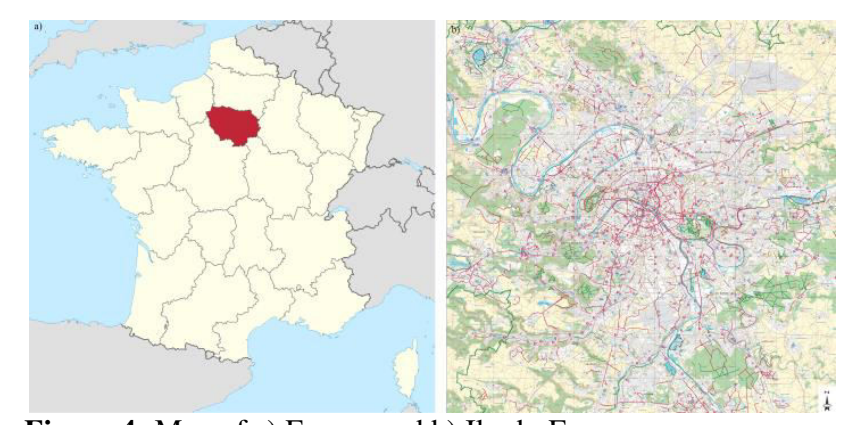

Figure 4. Map of a) France and b) Ile-de-France.

Recently, a report by the Organisation for Economic Cooperation and Development [40] highlights some major problems that could emerge in the case of floods. The concentration of strategic infrastructures in the area could represent an exacerbating factor that has been widely pointed out in literature [19, 35]. Indeed, it has been estimated that an extreme flooding event (return period of more than 100 years) in this area could have direct and indirect effects on several millions people and manifold industries and facilities. Potentially, it could disrupt the functioning of the institutions, as well as most of the critical infrastructures essential for the daily life of Paris. The distribution of electricity could be largely affected, with almost one quarter of power stations flooded and more than 1.5 million customers who could experience power cuts. The road network could be blocked, while drinking water supply may be interrupted with more than 5 million citizens suffering of extended water cuts and, at least, another 1.3 million a deterioration in quality. 
As visible in Figure 5, produced by the EPTB Seine Grands Lacs (the department responsible for water management) in 2014, several areas around Paris are classified as territory at significant risk of flooding. For this reasons and following the requirements of the FD, the EPTB has developed the PAPI, which is the programme to prevent and manage flooding events, and give advice to the involved water authorities to take actions in a coordinate and synergic way [41].

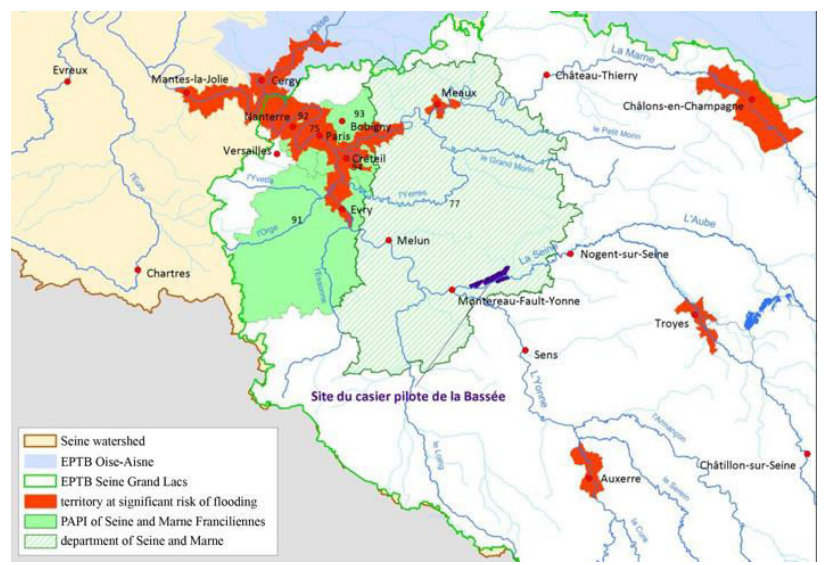

Figure 5. Territory subjected to flooding risk in the Ile-deFrance region (source [41]).

Nowadays, there is an on-going momentum on flood risk management with the FD implementation: a national strategy on the management of flood risks is being developed and a priority area for risk management in the Ile-de-France region was recently defined, together with a governance mechanism for its implementation [40].

\subsection{Cascading and risk assessment: York}

York's barriers were completed in 1987 following major flooding happened in 1982. Despite another event in 2000, no improvement were adopted and, in 2012, the use of four of their eight pumps failed for overheating, resulting in flood warnings for hundreds of householders. Following those episodes and the UK National strategy, the local City Council approved its own flood risk management strategy in March 2015 [42]. The document included a preliminary risk assessment (PFRA) explicitly based on the EU Floods Directive. One of its conclusions was that "no historical local flood events are considered to have had significant harmful consequences" [42]. Following this document, flood risk management plans had to be prepared by December 2015, but because the Council PFRA affirmed that York did not exceed the national flooding thresholds, "no further action was required in the current cycle" [42].

However, December 2015 was considered the wettest month ever recorder in the UK, with the rain falling almost double the average [43]. These precipitations triggered several flooding events across the country. Like in the past, the town of York was expected to be at risk across its entire territory, as reported by the Environment Agency in Figure 6b.

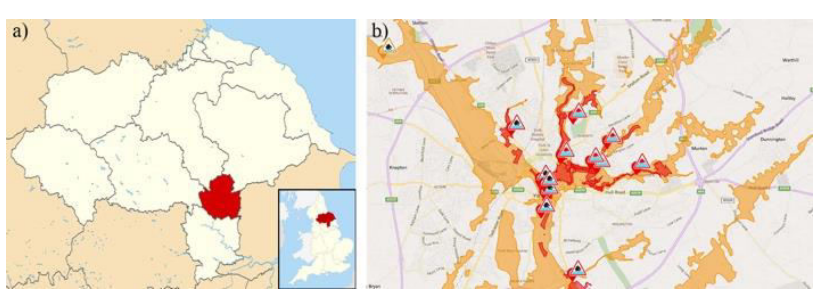

Figure 6. a) Map of York; b) Flood Risk Maps released by the Environment Agency on December 26, 2015.

The failure of some key flood defences in the north of Britain questioned the national capacity of coping with anomalous events. In several urban areas thousands of homes were revealed more at risk than was expected and in York the authorities forced the evacuation of thousands of citizens. The state of the large-scale defences was seriously affected, because pumping equipments were overwhelmed by the huge volume of water. Besides the coordination efforts related to evacuation and sheltering of citizens or the lack of ground transportation (more than thirty roads were completely closed), the official timeline of events highlighted another clear escalation point for operations. Since the evening of December 27 "Flood water swamps British Telecommunications (BT) exchange, phone internet and many mobile networks fail including hospital phones" [44]. The afternoon of December 28 the same timeline observed "underground telephone cables fault affecting 40000 customers" [44]. On December 29 the authorities suggested that the majority of domestic phone lines were restored, but 4000 customers were still without broadband. In other words, thousands of York homes and businesses were left without phone and internet services, creating what was called a "ghost town". The problems appeared to have impacted banking and payment services in the city, as observed by a BT spokesman, whom confirmed that phone and broadband services were lost due to severe flooding events in the Yorkshire area [45].

Although those circumstances may become more frequent due to climate change [46, 47], this case study verifies the evidences pointed out by Nones and Pescaroli [4]: current risk assessment procedures tends to focus only on hazards, underestimating the potential of cascading effects, despite the effective implementation of the advice reported in the FD. Moreover, the event described here confirmed the existence of a vulnerability path related to the role of CI as functional nodes, which trigger an escalation of emergencies, in line with the model described by Pescaroli and Alexander [23].

\subsection{Cascading and mismanagement: Messina}

In autumn 2015 the southern Italy was affected by huge rainfalls, in particular in the northern part of Sicily in the provinces of Messina and Catania (Figure 7). 


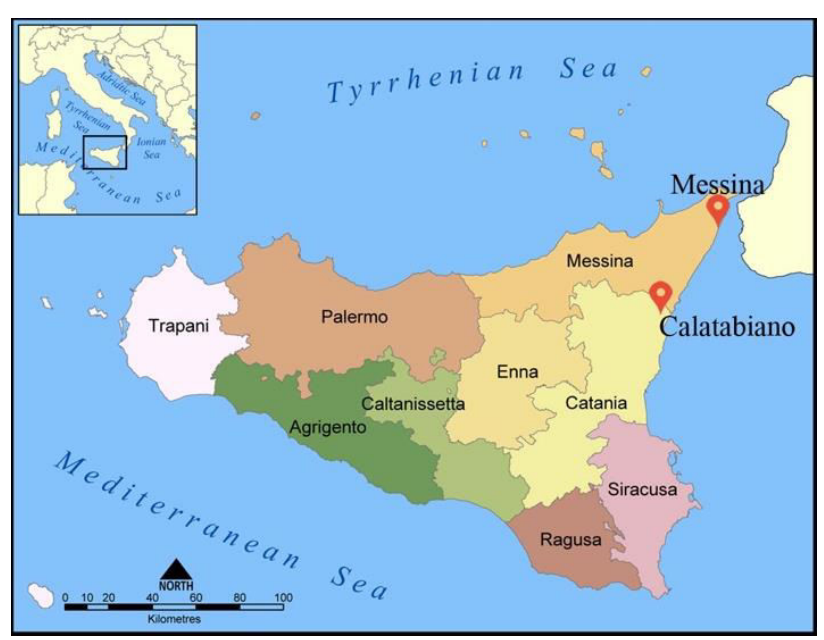

Figure 7. Map of Sicily, with location of Messina and Calatabiano.

In October 2015, excessive rains caused river overflows in the lowland areas and debris flows and landslides in the mountain part of the island [48]. After several raining days, on October 24 a landslide damaged a water pipe of the Fiumefreddo aqueduct, close to the village of Calatabiano, which is the main source of water for Messina, delivering about $80 \%(920 \mathrm{l} / \mathrm{s})$ of the drinking water consumed in the city.

Due to the lack of funds, insecure conditions of the impacted site, administrative and logistic delays, Messina suffered more than 20 days without drinking water [49]. The problem was partially reduced by the small supply delivered by tankers and the presence of a few old wells in the city. Moreover, schools and public offices were closed or disrupted [50], involving maddening consequences for the citizens. Besides such problems, landslides triggered by floods caused at least 2 billion euro of damages in the mountain area.

The relevance of this case study has to be referred to the clear presence of pre-existing factors and social feedbacks [24] that generated the vulnerability path of cascading [23]. Indeed, Messina has a long tradition of lack of drinkable water, which caused the recurrent effects of droughts, but also a well-known mismanagement of water supply system and control of the mountainous areas are clearly recognizable (e.g. [51, 52]).

Although the Floods Directive cannot address juridical problems, the integration of vulnerability assessment procedures would have helped to identify the most sensible infrastructures and the possible interactions with land use management. This was done only marginally in the local civil protection plan [53]. On the one hand, it did not consider the risk of concurrence or cascades triggered by a primary hazard as defined by Gill and Malamud [33]. On the other hand, the document did not integrate possible social consequences generated by CI disruptions, considering very vaguely only the risk of electric black out.

\subsection{Cascading and chemical escalation: Spolana plant and Gloucestershire}

Natural events may be a powerful and prominent mechanism of direct and indirect release of hazardous materials [54, 55]. If industrial sites are located in naturally hazard-prone areas, technological accidents may be triggered by natural happenings, which could generate NaTech disasters (Natural events triggering Technological Disasters). Such accidents can modify and increase the impact and the overall damages in the surrounding areas $[56,57,58,59]$.

The analysis of NaTech disasters reported in this paper is carried out through the consultation of the MARS database, which summarises data and information on accidents that occurred in process plants and industrial sites. The MARS (Major Accident Reporting System) database is managed by the Major Accident Hazards Bureau at the European Commission Joint Research Centre in Ispra, Italy [60]. This repository was established to comply with the obligations of Article 19 of the "Seveso-II" Directive 96/82/EC [61], which requires setting up a database in order to record and exchange data and information on the accidents that occurred in industrial sites. The reports come from the competent authorities and are divided in three sections: report profile, short report and full report. The report profile contains information to identify the event, while additional details are described in the other two sections, such as causes and circumstances of the accidents, evolution and consequences, adopted responses. Short reports, which are available to the public and therefore analysed in the present paper, summarise the main information concerning the accident. Full reports are confidential and contain more detailed data about the accidents, but they can be provided only after causes, evolution and consequences of the accident are fully understood [58]. In UK, the requirements of the "SevesoII" Directive have been implemented by the COMAH regulations 1999 [62]. The general duty of the COMAH regulations is that "every operator shall take all measures necessary to prevent major accidents and limit their consequences to the persons and the environment", classifying the sites and preparing on-site emergency plans.

In the following sections we present two case studies that influenced the early steps of the Floods Directive, pointing out possible problems triggered by flooding events. We use these case studies to highlight the points that are still unsolved in the implementation process.

\subsubsection{Spolana chemical plant}

The Spolana chemical plant is located at Neratovice, about $25 \mathrm{~km}$ north of Prague, Czech Republic, along the Elbe River (Figure 8). 


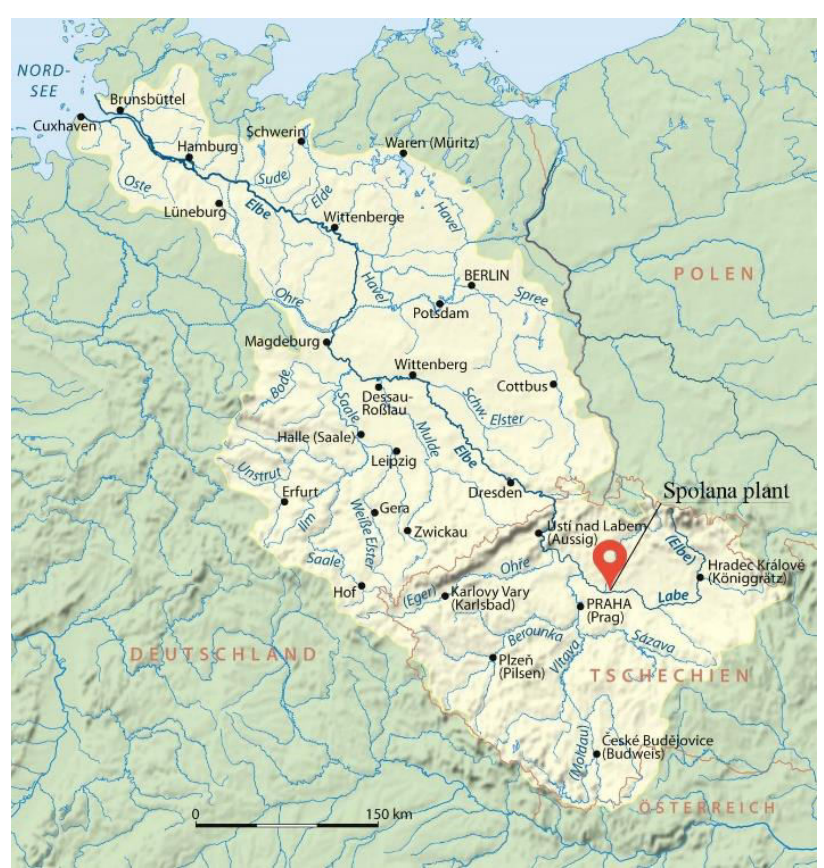

Figure 8. Map of the Elbe basin and localization of the Spolana plant.

Here, a chlor-alkali plant has been in operation since 1948 [63]. During the former communist regime, the plant produced chlorine and dioxins, creating one of the most contaminated places worldwide. Chlorine is a heavy gas with a pungent odor, which irritates mucous membranes even in small quantities, producing headaches, eye irritation and conjunctivitis, congestion of the membrane of respiratory organs, persistent cough and sharp pains in the breastbone. In greater concentration, there is a danger of edema or even death.

In August 2002, extreme and widespread precipitations over the Czech Republic and Eastern Germany led to disastrous floods in the catchment areas of the upper course of the Elbe River, the tributaries Vltava and Mulde [4, 64, 65]. As a consequence of a catastrophic flood characterized by a return time period of more than one century [66], about $90 \%$ of the Spolana factory area was flooded up to $3 \mathrm{~m}$, and there was a great risk of spreading of highly $\mathrm{Hg}$-contaminated materials within the area [55, 63]. In detail, between August 14 and August 18 water entered into the plant and inundated the emergency retention sumps, in which the liquid chlorine storage tanks were located. Therefore, chlorine was released into air and water on August 15, 17 and 23 [60]. On August 15, the rupture of a pipeline and the detachment of parts of a container caused the major release of chlorine, involving all the surrounding and creating damages to the vegetation and habitat, but, fortunately, without any injury to the workforce. It was estimated that, in total, more than 80000 tons of chlorine was released [60].

The measured concentration of several chemicals in the soils resulted increased after the flooding event with respect to the state before the episode [65, 67], creating long-term problems for the habitat and contaminating surface watercourses and groundwaters at large scale. In addition, the residential area near the chemical plant was covered by a toxic cloud for many days.

\subsubsection{Gloucestershire waste treatment facility}

The autumn of 2000 was considered, at that time, the wettest for around 270 years over England and Wales [68], and the prolonged heavy rainfall caused significant river flooding in many regions, such as the Gloucestershire (Figure 9a).

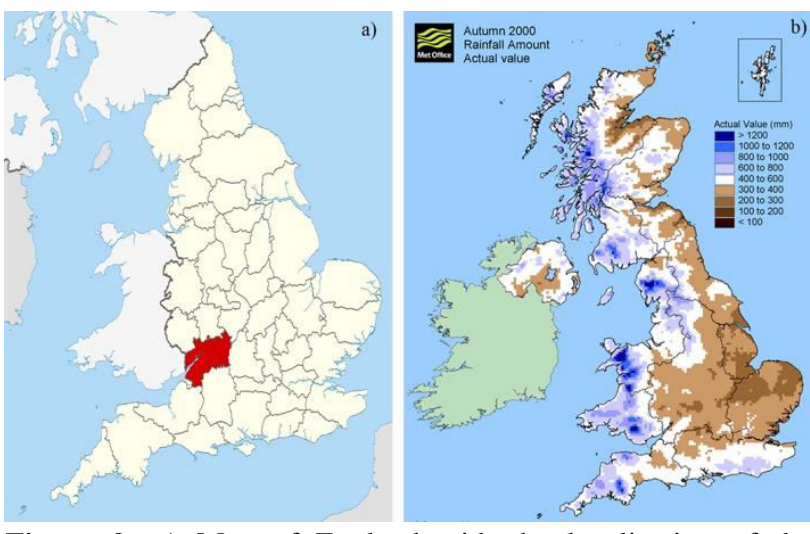

Figure 9. a) Map of England with the localization of the Gloucestershire; b) rainfall amount over England in autumn 2000 (source [68]).

These happenings contributed to a major accident that occurred at the waste treatment and storage site located in Sandhurst, near Gloucester. The site, classified as a COMAH lower tier plant, was a licensed waste treatment facility and transfer station for a wide range of hazardous waste chemical substances. The incident started in the early hours of October 30 during a severe storm, which triggered a major fire in a waste storage area [60]. Around 177 tons of mixed chemicals including flammables, toxics (1.1 ton), chlorinated hydrocarbon solvents, low-level radiation waste and asbestos were consumed by the fire. Fortunately, not all the materials involved were dangerous substances as defined in COMAH [62]. The fire was restricted to the waste transfer area and did not affect the bulk tanks store on site.

Most of the firewater was retained on site by containment measures, but a small quantity of polluted water escaped, with consequent problems to the surroundings. Despite of there were no on-site injuries or ill-health problems, numerous reports of illness to local residents have been reported after the event, but direct links with the incidents remain quite unclear. Several surveys and studies were performed in the area affected, in order to analyse the effect of the incident on biota and vegetation. So far, a few results are available, indicating a slight increase of the level of heavy metals in macroinvertebrates just after the event. No detailed data or additional information about the long-term effects of the accident on the environment are reported, but the Environment Agency is continuing its investigations.

Notwithstanding of the relatively low impact of this event, raised anxiety among residents about chemical contamination was a major issue [2]. There was a significant off-site concern, with the formation of local pressure groups, campaigning primarily to stop the site 
reopening. This was successful, as the site closed down following the incident [60].

\section{Discussion}

Our case studies provided a range of evidences from different cultural and social contexts. What emerges is a wide picture of the vulnerability path of cascading events, in line with the theory of Pescaroli and Alexander [23]. According to our results, the failure of $\mathrm{CI}$ and its technological components can escalate the events categorized in four interacting areas of sensibility (Figure 10):

- vulnerability of network. The functional vulnerability of heavily networked urban life to CI disruption can threat the functioning of manifold activities and delayed problems for citizens not directly affected by floods. The escalation process starts involving the area directly impacted by water, which amplifies at the regional and cross-border level. An exemplar case is the economic region Ile-de-France, which is based on deeply interconnected functions at high risk of flooding [69];

- vulnerability of society. The interdependencies of the built environment and vital functions suggest that traditional risk assessment process is, generally, not enough. The evidence is particularly clear in the York's case study, where it is possible to notice the failure of a strategy approved in the very same year of the event [42]; - vulnerability to interactions among environmental and human systems. This vulnerability is shown in the Messina case, where the mismanagement and the raise of anthropic pressures increase the likelihood of chain effects among hazard [33]. When it clashed with the rigidities accumulated in CI, like the lack of preparedness, a full cascade escalated in society [23];

- vulnerability to NaTech escalation. Flooding events on industrial sites located in naturally hazard-prone areas may be powerful triggers for technological accidents, modifying and increasing consequences and damages in the surrounding areas $[56,57]$.

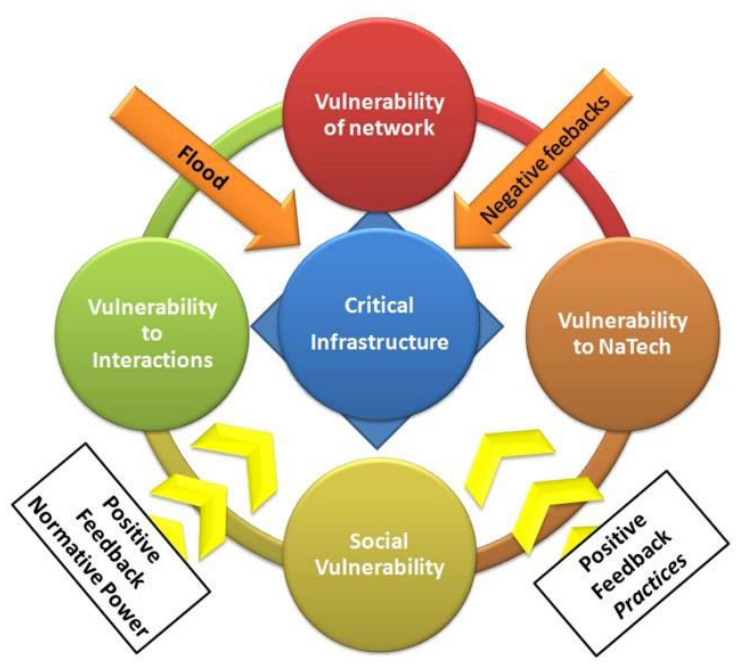

Figure 10. Interacting dimensions of vulnerability, CI and feedback loops in Cascading Disasters triggered by floods.
Those dimensions are probably not exhaustive and they are likely to be conditioned by the limited information available. However, they seem to confirm that the FD is missing to address the potential escalation of events that characterize cascading disasters. In fact, in every case described we notice the existence of feedback loops that could represent the root of cascading paths, but could also be a way to tackle them [23]. Therefore, we may argue that vulnerability can be reduced by: i) the use of normative power, intended as a way to modify the status quo; ii) the management, intended as a better planning and the improvement of lessons learned [24].

Recently, it has been shown that the FD seems to be missing to integrate the impact of cascading effects when they involve larger spatial and temporal scales [4]. In the case of cascading disasters, this is likely to be even more critical because the escalation process becomes stronger. As reported in Figure 11, flooding events in the Directive are associated with the primary impact of triggers, giving less attention to secondary effects and escalation processes. To tackle the challenges determined by crosstemporal and spatial scales of cascading paths, the diversification of efforts made by the water authorities in charge could be determinant.

The FD could benefit of integrating vulnerability scenario building instead of just being focused on risk and hazard scenarios, according with the theory of the vulnerability path [23]. This may be done in different ways. Firstly, new assessment methodologies should integrate together social, physical and structural drivers, taking as reference, respectively, the community, the environment and the buildings in defining the sensibility of areas to flood-triggered cascading. Secondly, GIS databases could be used to combine the likelihood of interactions among different hazards with variables such as the development of strategic land use planning or the level of maintenance and preparedness of CI. Finally, the presence of infrastructural nodes should take more relevance and be contextualized in their social, economic and ecological contexts. This may provide a better perspective on NaTech escalation, which is likely to have a more impact in areas of high pre-impact vulnerability.

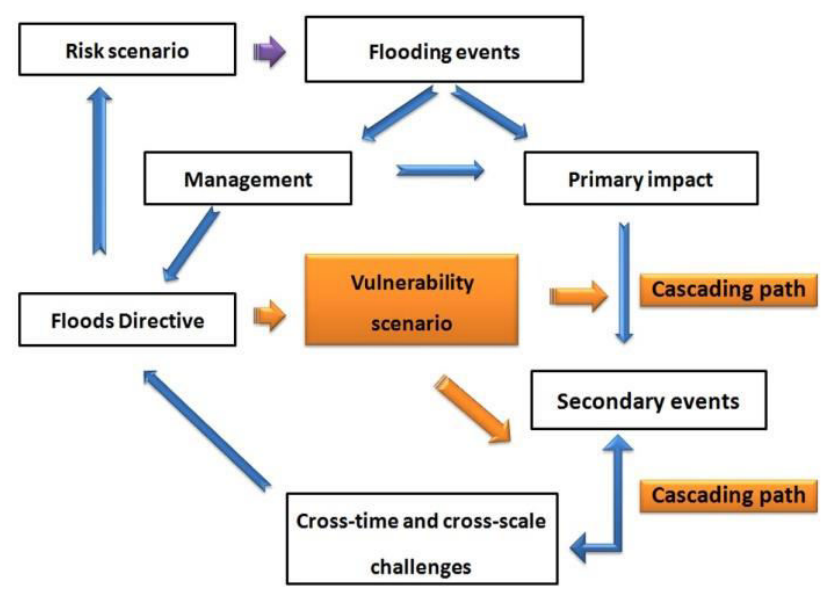

Figure 11. EU Floods Directive: from risk scenario to vulnerability scenario. 


\section{Conclusions}

In the paper we verified that the Floods Directive is missing to address the potential escalation of events that distinguishes cascading disasters. We pointed out the open challenges associated with cascading disasters and cross-scales interactions, on the basis of case studies chosen according to the standards suggested by King et al. [70], in order to guarantee replicability in future researches.

The analyses of these cases addressed different forms of escalation process, which could be ascribed at the European level with improvements in the frame of the EU Floods Directive. Our review suggests some priority areas where additional effort is necessary to fill the existing gaps: i) scientific limitations can generate high uncertainty or non-availability of data on the long-term impact of flooding events, especially when social vulnerability is implicated; ii) spatial and temporal scales result difficult to determine when trigger hazards cause the disruption of interconnected infrastructures; iii) the strong interdependence of natural/built environment and human pressures requires to improve the evaluation of risk scenarios; iv) floods management needs the consideration of secondary and indirect effects, which are generally underestimated by policy makers and water managers; v) the training of adequate experts able to provide new categories of information should be considered; vi) the integration of vulnerability scenario should account for different contextual drivers, becoming a new tool used by normative power and management to address the escalation process.

To sum up, we can argue that the Floods Directive should include a higher balance between the evaluation of hazards and the management of vulnerability scenarios, with the aim to provide better advice to water managers in addressing the coordination challenges that could arise in the case of cross-scale crisis where cascades are diffused. Future flood risk management plans could integrate the impact of flooding events at larger spatial and temporal scales, considering all the possible crosstime and cross-scale challenges that can arise from flooding events. A better integration of common standards used for vulnerability assessment process in the Floods Directive implementation seems necessary, in particular on the basis of some priorities: i) use of maps and rankings that include CI interdependencies; ii) consideration of stressors that could amplify the impact of the events including social and environmental vulnerabilities; iii) attention on economic drivers and environmental features that could generate cross-scale escalation.

This paper represents a preliminary overview on the relationship between cascading events and Floods Directive, therefore it is not pretended to be exhaustive. Further research is needed to define how and in which form a better understanding of vulnerabilities can improve the effectiveness of mitigation measures and preparedness practices. The work for a better integration of cascading paths in the present legislation is just begun.

\section{References}

1. de Moel H., van Alphen J. and Aerts J.C.J.H. (2009). Flood maps in Europe - methods, availability and use. Natural Hazards and Earth System Sciences, 9, 289-301

2. Euripidou E. and Murray V. (2004). Public health impacts of floods and chemical contamination. Journal of Public Health, 26(4), 376-383

3. Munich RE (2005). Weather catastrophes and climate change. Münchener RückversicherungsGesellschaft. Munich, Germany

4. Nones M. and Pescaroli G. (2016). Implications of cascading effects for the EU Floods Directive. Int. Journal of River Basin Management. in press. doi: 10.1080/15715124.2016.1149074

5. Klijn F., Samuels P. and Van Os A. (2008). Towards flood risk management in the EU: state of affairs with examples from various European countries. International Journal of River Basin Management, 6(4), 307-321

6. Kundzewicz Z.W., Mata L.J., Arnell N.W., Döll P., Kabat P., Jimenez B., Miller K.A., Oki T., Sen Z. and Shiklomanox I. A. (2007). Freshwater resources and their management. in Climate change 2007: Impacts, Adaptation and Vulnerability. Contribution of Working Group II to the Fourth Assessment Report of the Intergovernmental Panel on Climate Change. edited by Parry M.L., Canziani O.F., Palutikof J.P., van der Linden P.J. and Hanson C.E. Cambridge University Press, Cambridge, UK

7. Milly P.C.D., Wetherald R.T., Dunne K.A. and Delworth T.L. (2002). Increasing risk of great floods in a changing climate. Nature, 415, 514-517

8. Tunstall S.M., Johnson C.L., and Penning-Roswell E.C. (2004). Flood Hazard Management in England and Wales: from land drainage to flood risk management. World congress on Natural Disaster Mitigation, New Delhi, India.

9. Parker D.J., Priest S.J., and Tapsell S.M. (2009). Understanding and enhancing the public's behavioral response to flood warning information. Meteorological Applications, 16(1), 103-114

10. Pescaroli G. and Magni M. (2015). Flood Warnings in Coastal Areas: How Do Social and Behavioural Patterns Influence Alert Services? Natural Hazards Earth System Science, 15, 703-714

11. Heintz M.D., Hagemeier-Klose M. and Wagner K. (2012). Towards a Risk Governance Culture in Flood Policy - Findings from the Implementation of the "Floods Directive" in Germany. Water, 4(1), 135156

12. Merz B., Hall J., Disse M. and Schuman A. (2010). Fluvial flood risk management in a changing world. Natural Hazards Earth System Sciences, 10(3), 509527

13. Batica J. and Gourbesville P. (2014). Flood Resilience Index - methodology And Application. International Conference of Hydroinformatics, paper 433

14. DKKV (2004). Flood Risk Reduction in Germany lessons learned from the 2002 disaster in the Elbe 
region. Deutsches Komitee für Katastrophenvorsorge e.V. $(D K K V)$. Bonn, Germany

15. Roos A. and Van der Geer I. (2008). New approaches for flood risk management in the Netherlands. Proceedings of the $4^{\text {th }}$ International Symposium on Flood Defence, 6-8 May 2008, Toronto, Canada

16. Bubeck P., Kreibich H., Penning-Rowsell E.C., Botzen W.J.W., De Moel H. and Klijn F. (2015). Explaining differences in flood management approaches in Europe and in the USA - a comparative analysis. Journal of Flood Risk Management. in press. doi: 10.1111/jfr3.1215

17. European Union (2007). Directive 2007/60/EC of the European Parliament and of the Council of 23 October 2007 on the Assessment and the Management of Flood Risks. Official Journal L288, 6.11.2007.

18. Van Alphen J., Martini F., Loat R., Slomp R. and Passchier R. (2009). Flood Risk Mapping in Europe, experiences and best practices. Journal of Flood Risk Management, 2(4), 285-292

19. Pescaroli G. and Alexander D.E. (2015). A definition of cascading disaster and cascading effects: Going beyond the "toping dominos" metaphor. Planet@Risk, 2(3), 1-4

20. Müller U. (2013). Implementation of the Flood Risk management Directive in Selected European Countries. International Journal of Disaster Risk Science, 4(3), 115-125

21. Nones M. (2015). Implementation of the Floods Directive in selected EU Member States. Water and Environmental Journal, 29(2), 412-418

22. Birkmann J., Kienberger S. and Alexander D.E. (2014). Assessment of Vulnerability to Natural Hazards: A European Perspective. Eds. Elsevier.

23. Pescaroli G. and Alexander D.E. (2016). Critical infrastructure, panarchies and the vulnerability paths of cascading disasters. Natural Hazards, 1-18. doi: $10.1007 / \mathrm{s} 11069-016-2186-3$

24. Alexander D.E. (2000). Confronting Catastrophe. Terra Publishing, Harpenden. Oxford University Press, New York

25. European Commission (2008). Council Directive 2008/114/EC of 8 December 2008 on the identification and designation of European critical infrastructures and the assessment of the need to improve their protection. Official Journal L 345/75

26. Burzel A., Hounjet M., Becker B.P.J., Di Pietro A. and Pollino M. (2014). Towards A Decision Support System For Consequence Analysis of Flooding On Critical Infrastructure. International Conference of Hydroinformatics, paper 99.

27. Evers M. and Nyberg L. (2013). Coherence and inconsistency of European instruments for integrated river basin management. International Journal of River Basin Management, 11(2), 139-152

28. Dráb A. and Ǩ́lha J. (2010). An approach to the implementation of European Directive 2007/60/EC on flood risk management in the Czech Republic, Natural Hazards Earth System Sciences, 10, 19771987
29. Birkmann J. and Von Teichman K. (2010). Integrating disaster risk reduction and climate change adaptation: key challenges-scales, knowledge, and norms. Sustainability Science, 5(2), 171-184

30. Khan F.I. and Abbasi S.A. (2000). Studies on the probabilities and likely impacts of chains of accident (domino effect) in a fertilizer industry. Process Safety Progress, 19(1), 40-56

31. May F. (2007). Cascading Disaster Models in Postburn Flash Flood. in Butler B.W., Cook W. The Fire Environment - Innovations, Management and Policy; Conference Proceedings. US Department of Agriculture Forest Service, Washington, DC, 446463

32. Helbing D. (2013). Globally networked risks and how to respond. Nature, 497(7447), 51-59

33. Gill J.C. and Malamud B.D. (2016). Hazard Interactions and Interaction Networks (Cascades) within Multi-Hazard Methodologies. Earth System Dynamics Discussion. doi:10.5194/esd-2015-94

34. Hellström T. (2007). Critical infrastructure and systemic vulnerability: towards a planning framework. Safety Science, 45(3), 415-430

35. Ansell C., Boin A. and Keller A. (2010). Managing Transboundary Crises: Identifying the Building Blocks of an Effective Response System. Journal of Contingencies and Crisis Management, 18(4), 195207

36. Labaka L., Hernantes J. and Sarriegi J.M. (2016). A holistic framework for building critical infrastructure resilience. Technological Forecasting \& Social Change, 103, 21-33

37. Tockner K., Pusch M., Borchardt D. and Lorang M.S. (2010). Multiple stressors in coupled riverfloodplain ecosystems. Freshwater Biology 55(1), 135-151

38. Slowik M. (2015). Is history of rivers important in restoration projects? The example of human impact on a lowland river valley (the Obra River, Poland). Geomorphology, 251, 50-63

39. European Union (2000). Directive of the European Parliament and of the Council 2000/60/EC Establishing a Framework for Community Action in the Field of Water Policy, Official Journal C513, 23.10.2000

40. OECD (2014). Reviews of Risk Management Policies: Seine Basin, Ile-de-France. Resilience to Major Floods. Main Results and Recommendations

41. EPTB Seine Grands Lacs (2014). Programme d'actions de prévention des inondations de la Seine et de la Marne Franciliennes (PAPI). Synthesis

42. City of York (2015a). Local Flood Risk Management Strategy. Approved by the Cabinet in date 03/03/2015. Available at: http://democracy.york

43. Met Office (2015). December 2015. Daily Weather Summary. Available at http://www.metoffice.gov.uk/ learning/library/publications/daily-weather-summary

44. City of York (2015b). Flooding in York-Timeline. City of York. Available at: https://www.york.gov.uk /info/20149/emergencies/1808/floods

45. The Guardian (2015). UK floods 2015: York suffers phone and internet outages. Available at 
http://www.theguardian.com/uknews/2015/dec/28/uk -floods-2015-york-suffers-phone-internet-outagescash-machines

46. Ashton V., Aziz H., Keith S. and Smith T. (2003). Review of EU Flood R\&D Projects. Report prepared as a part of the group management project on the M.Sc. Water Resources Technology and Management Course, University of Birmingham, Department of Civil Engineering, Birmingham

47. Kay A.L., Davies H.N., Bell V.A. and Jones R.G. (2009). Comparison of uncertainty sources for climate change impacts: flood frequency in England. Climatic Change, 92(1-2), 41-63

48. Comune di Messina (2015a). Allerta meteo. Ordinanza del Sindaco n. 215 del 14 ottobre 2015. Available at http://www.comune.messina.it/inevidenza/avvisi/protezione-civile/ordinanza-15-102015.pdf. in Italian

49. La Repubblica (2015). Frana a monte delle condutture, tutta Messina resta senz'acqua. Available at http://palermo.repubblica.it/cronaca/2015/10/25/ news/frana_a_monte_delle_condutture_tutta_messin a_resta_senz_acqua-125857680. in Italian

50. Comune di Messina (2015b). Chiusura uffici comunali. Determinazione del Segretario Generale n. 467 del 26 ottobre 2015. Available at: http://www.comune.messina.it/in-evidenza/avvisi/ allegati-segreteria/determinazione-n-467-chiusurauffici-comunali-motivi-igienico-sanitari.pdf.

in Italian

51. OPCM (2009a). Ordinanza del Presidente del Consiglio dei Ministri n. 3815/2009 - Emergenza Messina. in Italian

52. OPCM (2009b). Ordinanza del Presidente del Consiglio dei Ministri n. 3734/2009 - Interventi eventi atmosferici novembre/dicembre 2008. in Italian

53. Comune di Messina (2008). Piano Comunale di Protezione Civile per la Città di Messina. Available at: $\quad$ http://www.comune.messina.it/protezionecivile/documenti/rischio-sismico/piano-emergenzamessina.pdf. in Italian

54. Young S., Balluz L. and Myers M.F. (2004). Natural and technologic hazardous material releases during and after natural disasters: a review. Science of The Total Environment, 322(1/3), 3-20

55. Marzo E., Busini V. and Rota R. (2012). Definition of a shortcut methodology for assessing flood-related Na-Tech risk. Natural Hazards and Earth System Sciences, 12, 3241-3253

56. Shaluf I.M. (2007). An overview on the technological disasters. Disaster Prevention and Management, 16(3), 380-390

57. Galderisi A., Ceudech A. and Pistucci M. (2008). A method for na-tech risk assessment as supporting tool for land use planning mitigation strategies. Natural Hazards, 46(2), 221-241

58. Cozzani V., Campedel M., Renni E. and Krausmann E. (2010). Industrial accidents triggered by flood events: Analysis of past accidents. Journal of Hazardous Materials, 175(1-3), 501-509
59. Krausmann E., Renni E., Campedel M. and Cozzani, V. (2011). Industrial accidents triggered by earthquakes, floods and lightning: lessons learned from a database analysis. Natural Hazards, 59(1), 285-300

60. European Commission, Joint Research Centre (2015). Major Accident Reporting System (MARS). Institute for the Protection and Security of the Citizen, Major Accident Hazards Bureau. Accessed 16 December 2015. Available at https://emars.jrc.ec.europa.eu/

61. European Commission (1996). Council Directive 1996/82/EC of 9 December 1996 on the control of major-accident hazards involving dangerous substances. Official Journal L10, 14.1.1997

62. Whitfield A. (2002). COMAH and the Environment: Lessons Learned from Major Accidents 19992000. Process safety and environmental protection, 80(1), 40-46

63. Suchara I. and Sucharová J. (2008). Mercury distribution around the Spolana chlor-alkali plant (central Bohemia, Czech Republic) after a catastrophic flood, as revealed by bioindicators. Environmental Pollution, 151(2), 352-361

64. Ulbrich U., Brücher T., Fink A.H., Leckebusch G.C., Krüger A. and Pinto J.G. (2003). The central European floods of August 2002: Part 1 - Rainfall periods and flood development. Weather, 58(10), 371-377

65. Stachel B., Jantzen E., Knoth W., Krüger F., Lepom P., Oetken M., Reincke H., Sawal G., Schwartz R. and Uhlig S. (2005). The Elbe Flood in August 2002 - Organic Contaminants in Sediment Samples Taken After the Flood Event. Journal of Environmental Science and Health, 40(2), 265-287

66. Hudec P. and Luks O. (2004). Flood at Spolana a-s in August 2002. Loss Prevention Bulletin (LPB), Sample papers, LPB180, 36-39

67. Vácha R., Polácek O. and Horváthová V. (2003). State of contamination of agricultural soils after floods in August 2002. Plant Soil and Environment, 49(7), 307-313

68. Met Office (2000). The autumn 2000 rains and floods. Post 151, Post Note, December 2000

69. Crichton, D. (2008). Role of Insurance in Reducing Flood Risk. The Geneva Papers, 33, 117-132

70. King G., Keohane R. and Verba S. (1994). Designing Social Inquiry. Princeton University Press, Princeton.

\section{Acknowledgements}

The work of Gianluca Pescaroli has been carried out under the aegis of the EC FP7 FORTRESS project. FORTRESS is funded by the European Commission within FP7-Area 10.4.1 'Preparedness, prevention, mitigation and planning', TOPIC SEC-2013.4.1-2, SEC2013.2.1-2, Grant 607579.

The work performed by Michael Nones was supported by the Research Executive Agency, through the $7^{\text {th }}$ Framework Programme of the European Union, 
Support for Training and Career Development of Researchers (Marie Curie - FP7-PEOPLE-2012-ITN), which funded the Initial Training Network (ITN) HYTECH "Hydrodynamic Transport in Ecologically Critical Heterogeneous Interfaces", N. 316546. 